\title{
DAMPAK PENAMBANGAN PASIR TERHADAP KONDISI LAHAN DAN AIR DI KECAMATAN SUKARATU KABUPATEN TASIKMALAYA
}

\section{Impact of Sand Mining to the Land and Water Conditions at Sukaratu Sub District, Tasikmalaya District}

\author{
Dini Widyasmarani Suherman ${ }^{\mathrm{a}}$, Dyah Tjahyandari Suryaningtyas ${ }^{\mathrm{b}}$, Sri Mulatsih $^{\mathrm{c}}$ \\ a Program Studi Pengelolaan Sumberdaya Alam dan Lingkungan, Sekolah Pascasarjana Institut Pertanian Bogor, \\ Bogor 16680 _diniwidyasmarani@yahoo.co.id \\ ${ }^{b}$ Departemen Ilmu Tanah dan Sumberdaya Lahan, Fakultas Pertanian, Institut Pertanian Bogor, Kampus IPB \\ Darmaga, Bogor 16680 \\ ${ }^{c}$ Departemen Ilmu Ekonomi, Fakultas Ekonomi, Institut Pertanian Bogor, Kampus IPB Darmaga, Bogor 16680
}

\begin{abstract}
Sand is an important commodity for constructions. The largest sand mining in Tasikmalaya District is located in Sukaratu Sub District. This mining activites have a negative impact for the environment such as causing erosion and water pollution. This study was aimed to assess the impact of sand mining on the land and water conditions. The analysis method that was used in this study is the analysis of erotion rate using Universal Soil Loss Equation (USLE) formula and the analysis of Total Suspended Solid (TSS) parameters. The results showed that the rate of erosion ranged from 163.49 to 1,194.16 ton/ha/year, with erosion hazard rate (TBE) were very heavy. The TSS value of Cibanjaran and Cikunir river water ranged from 26 to $186 \mathrm{mg} /$ liter, this values were below the threshold but the effect is not good for the fishery.
\end{abstract}

Keywords: erosion rate, sand mining, Total Suspended Solid (TSS)

(Diterima: 13-11-2014; Disetujui: 14-08-2015)

\section{Pendahuluan}

Pasir merupakan komoditas tambang yang berperan penting sebagai bahan baku material untuk berbagai pembangunan infrastruktur. Kabupaten Tasikmalaya adalah salah satu daerah yang memiliki potensi sumberdaya pasir yang cukup melimpah. Penambangan pasir terbesar di Kabupaten Tasikmalaya terletak di Kecamatan Sukaratu. Usaha penambangan pasir sudah dilakukan sejak tahun 1982, setelah terjadinya letusan Gunung Galunggung. Penambangan pasir dilakukan masyarakat sekitar secara manual dan perusahaan penambangan skala besar.

Penambangan pasir dapat menyerap tenaga kerja (Yudhistira 2008) dan tumbuhnya kesempatan berusaha masyarakat sekitar (Dyahwanti 2007). Selain itu, penambangan pasir juga memberikan kontribusi bagi daerah sebagai salah satu sumber Pendapatan Asli Daerah (PAD). Produk Domestik Regional Bruto (PDRB) atas dasar harga berlaku tahun 2013 dari sektor pertambangan dan penggalian sebesar Rp 33,253.21 juta (BPS Kab. Tasikmalaya 2014).

Namun, apabila penambangan pasir tidak dikelola dengan baik maka akan menimbulkan dampak negatif pada keseimbangan dan fungsi lingkungan seperti menyebabkan terjadinya pengikisan terhadap humus tanah, terbentuknya lubang-lubang besar dan mengakibatkan erosi (Hasibuan 2006). Erosi merupakan proses alami yang mudah dikenali, akan tetapi erosi bisa diperparah oleh aktivitas manusia (Arsyad 2006) seperti kegiatan penambangan pasir karena pada kegiatan ini terjadi perubahan tutupan lahan menjadi lahan terbuka, sehingga tingkat erosi di daerah penambangan pasir termasuk tinggi (Yudhistira 2008). Selain itu, penambangan pasir dapat menyebabkan pencemaran lingkungan perairan (Yunus 2005; Sonak et al. 2006). Penambangan pasir di kawasan Galunggung dilakukan dengan sistem penambangan terbuka yang terdiri dari beberapa tahapan proses, salah satunya adalah proses pencucian yang dilakukan untuk memisahkan pasir dari unsur-unsur lainnya dan menghasilkan sisa pencucian berupa lumpur dan pasir halus. Widyati dan Rostiwati (2010) mengemukakan bahwa persoalan akan menjadi serius ketika sisa pencucian tersebut mengalir masuk ke sungai. Salah satu faktor inilah yang mempengaruhi kualitas air sungai di sekitar lokasi penambangan pasir. Berdasarkan hal tersebut, maka penelitian mengenai kegiatan penambangan pasir di Kecamatan Sukaratu perlu dilakukan dengan tujuan untuk mengkaji dampak penambangan pasir terhadap kondisi lahan yang dilihat dari laju erosi dan kondisi air yang dilihat dari parameter Total Suspended Solid (TSS).

\section{Metode Penelitian}

Penelitian dilakukan di Desa Linggajati, Tawangbanteng dan Gunungsari, Kecamatan Sukaratu, Kabupaten Tasikmalaya pada bulan Mei sampai dengan Juni 2014. Sampel yang diambil adalah sampel tanah dan air. Sampel tanah diambil pada 6 lokasi penambangan yaitu A1, A2 dan A3 yang berada pada tingkat kemiringan lereng $8-15 \%$ dan B1, B2 dan B3 yang berada pada tingkat kemiringan lereng 0-8\%. Sampel air adalah air 
sungai Cibanjaran dan Cikunir yang diambil di 3 titik pada masing-masing sungai (sebelum lokasi penambangan, lokasi penambangan dan setelah lokasi penambangan) serta masing-masing 1 titik di kolam milik masyarakat yang menggunakan air sungai tersebut. Lokasi penelitian dapat dilihat pada Gambar 1 .

Penentuan laju erosi dilakukan dengan menggunakan rumus Universal Soil Loss Equation (USLE) yang dikembangkan oleh Wischmeier dan Smith (1978) dalam Hardjowigeno dan Widiatmaka (2007). Adapun rumusnya adalah sebagai berikut:

$$
A=R K L S C P
$$

keterangan:

A = banyaknya tanah tererosi (ton/ha/tahun)

$\mathrm{R}=$ faktor erosivitas hujan dan aliran permukaan $(\mathrm{MJ}$ $\mathrm{mm} / \mathrm{ha} / \mathrm{jam} /$ tahun)

$\mathrm{K}$ = faktor erodibilitas tanah (ton ha jam $/ \mathrm{MJ} / \mathrm{mm} / \mathrm{ha}$ )

$\mathrm{LS}=$ faktor panjang dan kemiringan lereng

$\mathrm{C}=$ faktor vegetasi penutup tanah dan pengelolaan tanaman

$\mathrm{P}=$ faktor tindakan konservasi tanah

Data curah hujan diperoleh dari Pos Pengamatan Gunung Api Galunggung, Pusat Vulkanologi dan Mitigasi Bencana Geologi, Badan Geologi (Kementerian ESDM RI). Data curah hujan yang dipakai adalah data curah hujan bulanan sepuluh tahun terakhir dari mulai tahun 2004 sampai dengan 2013. Nilai R diperoleh dengan menjumlahkan erosivitas hujan bulanan (RM) selama setahun. Perhitungan RM dilakukan dengan menggunakan rumus sebagai berikut:

$$
R M=2.21(\text { Rain }) m^{1.36}
$$

keterangan:

$\mathrm{RM}=$ erosivitas hujan bulanan

(Rain)m = curah hujan bulanan $(\mathrm{cm})$

Pengujian sampel tanah dilakukan di Laboratorium Kesuburan Tanah dan Nutrisi Tanaman, Universitas Padjadjaran. Hasil analisis sampel tanah tersebut diperlukan untuk menghitung nilai erodibilitas tanah (K). Nilai erodibilitas tanah dilakukan dengan menggunakan rumus sebagai berikut:

$$
K=\frac{2.713 M^{1.14}(10)^{-4}(12-a)+3.25(b-2)+2.5(c-3)}{100}
$$

keterangan:

$\mathrm{K}=$ erodibilitas tanah

$\mathrm{M}=$ parameter ukuran butir $(\%$ debu $+\%$ pasir sangat halus)(100 - \%liat)

$\mathrm{a}=\%$ bahan organik $(\% \mathrm{C} \times 1.724)$

$\mathrm{b}=$ kode (nilai) struktur tanah (lihat Tabel 1)

c $=$ kode (nilai) permeabilitas tanah (lihat Tabel 2)

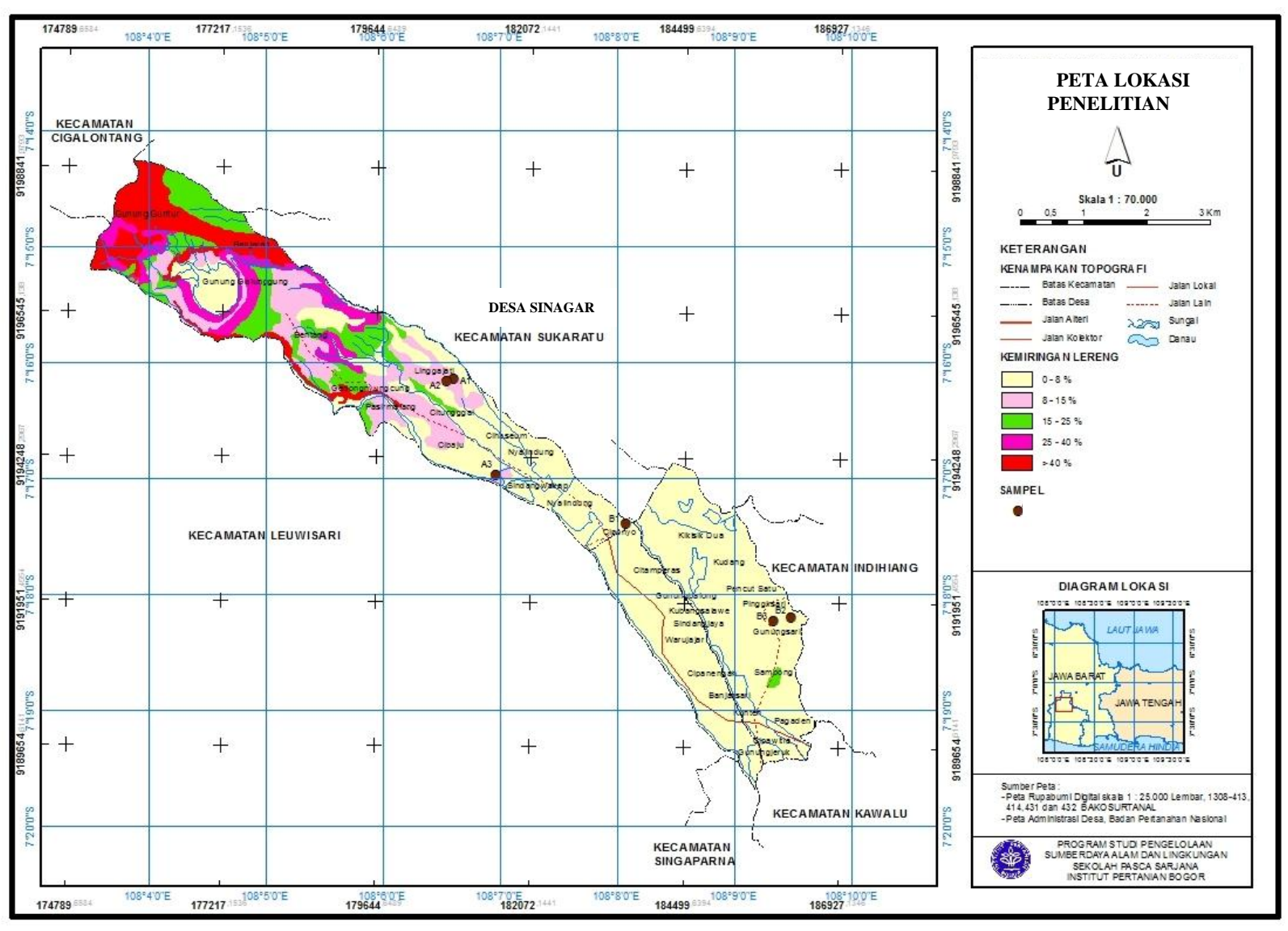

Gambar 1. Peta lokasi penelitian 
Tabel 1. Penilaian struktur tanah

\begin{tabular}{cc}
\hline Tipe struktur tanah & Nilai struktur tanah (b) \\
\hline Granular sangat halus (very fine granular) & 1 \\
\hline Granular halus (fine granular) & 2 \\
\hline Granular sedang dan kasar (medium, coarse granular) & 3 \\
\hline Gumpal, lempeng, pejal (blocky, platy, massif) & 4 \\
\hline
\end{tabular}

Sumber: Hammer (1978) dalam Hardjowigeno dan Widiatmaka (2007)

Tabel 2. Penilaian permeabilitas tanah

\begin{tabular}{ccc}
\hline Kelas permeabilitas & Permeabilitas (cm/jam) & Nilai permeabilitas (c) \\
\hline Cepat (rapid) & $>25.4$ & 1 \\
\hline Sedang sampai cepat (moderate to rapid) & $12.7-25.4$ & 2 \\
\hline Sedang (moderate) & $6.3-12.7$ & 3 \\
\hline Sedang sampai lambat (moderate to slow) & $2.0-6.3$ & 4 \\
\hline Lambat (slow) & $0.5-2.0$ & 5 \\
\hline Sangat lambat (very slow) & $<0.5$ & 6 \\
\hline
\end{tabular}

Sumber: Hammer (1978) dalam Hardjowigeno dan Widiatmaka (2007)

Tabel 3. Curah hujan bulanan dari tahun 2004-2013 dan erosivitas hujan bulanan (RM)

\begin{tabular}{ccccccccccccc}
\hline Bulan & $\mathbf{2 0 0 4}$ & $\mathbf{2 0 0 5}$ & $\mathbf{2 0 0 6}$ & $\mathbf{2 0 0 7}$ & $\mathbf{2 0 0 8}$ & $\mathbf{2 0 0 9}$ & $\mathbf{2 0 1 0}$ & $\mathbf{2 0 1 1}$ & $\mathbf{2 0 1 2}$ & $\mathbf{2 0 1 3}$ & Rata-rata & $\begin{array}{c}\text { Erosivitas } \\
\text { hujan } \\
\text { (RM) }\end{array}$ \\
\hline Januari & 475 & 442 & 486 & 620 & 172 & 592 & 561.5 & 196 & 341 & 325 & 421.05 & 357.67 \\
\hline Februari & 232.5 & 243 & 395 & 303 & 146 & 325 & 814 & 306 & 366 & 367 & 349.75 & 277.91 \\
\hline Maret & 622 & 340 & 167 & 380 & 465 & 605 & 692 & 383 & 198 & 587 & 443.90 & 384.33 \\
\hline April & 414 & 465 & 535 & 520 & 271 & 233 & 459 & 291 & 361 & 424 & 397.30 & 330.52 \\
\hline Mei & 356 & 220 & 435 & 243 & 152 & 259 & 497 & 338 & 223 & 456 & 317.90 & 244.07 \\
\hline Juni & 113.5 & 309 & 44 & 227 & 65 & 249 & 219 & 76 & 38 & 294 & 163.45 & 98.76 \\
\hline Juli & 175.5 & 190 & 109 & 65 & 14 & 116 & 299 & 203 & 11 & 364 & 154.65 & 91.60 \\
\hline Agustus & 4 & 336 & 56 & 25.5 & 40 & 3 & 531 & 17 & 0 & 18.5 & 103.10 & 52.77 \\
\hline September & 153 & 236 & 3 & 19 & 125 & 71 & 615 & 4 & 25 & 74 & 132.50 & 74.23 \\
\hline Oktober & 59 & 551 & 15 & 370 & 509 & 411 & 491 & 238 & 153 & 148 & 294.50 & 219.96 \\
\hline November & 497 & 288 & 199 & 316 & 606 & 577 & 586 & 511 & 531 & 154 & 426.50 & 363.98 \\
\hline Desember & 518 & 256 & 488 & 407 & 401.5 & 361 & 624 & 323 & 416 & 327 & 412.15 & 347.43 \\
\hline Jumlah & $3,619.5$ & 3,876 & 2,932 & $3,495.5$ & $2,966.5$ & 3,802 & $6,388.5$ & 2,886 & 2,663 & $3,538.5$ & $3,616.75$ & $2,843.24$ \\
\hline
\end{tabular}

Sumber: Pos Pengamatan Gunung Api Galunggung-Pusat Vulkanologi dan Mitigasi Bencana Geologi-Badan Geologi (Kementerian ESDM RI) dan Analisis Data Primer (2014)

Kemiringan lereng diperoleh dengan melakukan overlay letak lokasi penambangan pada peta lereng. Berdasarkan hasil pengamatan di lapangan, lokasi penambangan merupakan tanah terbuka tanpa tanaman, sehingga nilai faktor vegetasi penutup tanah/tutupan lahan (C) maupun nilai faktor konservasi tanah (P) masing-masing adalah 1.00 (Arsyad 2006). Setelah diperoleh nilai laju erosi (A) selanjutnya diklasifikasikan Tingkat Bahaya Erosinya (TBE). TBE diklasifikasikan dengan menggunakan kriteria Departemen Kehutanan (1986) dalam Hardjowigeno dan Widiatmaka (2007).

Untuk mengetahui dampak penambangan pasir terhadap kondisi air, sampel dianalisis di Laboratorium Badan Pengendalian Lingkungan Hidup (BPLH) Kabupaten Ciamis. Hasil analisis tersebut kemudian dibandingkan dengan baku mutu perairan sesuai peruntukannya berdasarkan Peraturan Pemerintah Nomor
82 Tahun 2001 tentang Pengelolaan Kualitas Air dan Pengendalian Pencemaran Air.

\section{Hasil dan Pembahasan}

\subsection{Erosivitas Hujan}

Data curah hujan dan nilai erosivitas hujan bulanan (RM) disajikan pada Tabel 3. Berdasarkan Tabel 3, curah hujan rata-rata termasuk tinggi yakni sebesar 3,616.75 $\mathrm{mm}$ dengan curah hujan rata-rata tertinggi pada bulan Maret dan curah hujan rata-rata terendah pada bulan Agustus. Nilai erosivitas hujan (R) sebesar 2,843.24. Nilai R ini berlaku untuk semua titik lokasi. Nilai erosivitas tinggi dikarenakan intensitas curah hujan yang cukup tinggi juga. Tinggi rendahnya 
intensitas hujan akan mempengaruhi besar kecilnya erosivitas hujan.

Menurut Dariah et al. (2004), tanah akan semakin peka terhadap erosi, karena curah hujan di Indonesia pada umumnya tinggi, berkisar dari 1,500-3,000 mm atau lebih setiap tahunnya, dengan intensitas hujannya yang juga tinggi. Erosivitas hujan yang tinggi biasanya spesifik untuk berbagai wilayah. Pengaruh erosivitas yang tinggi dapat dikurangi dengan jalan melemahkan energi kinetik butiran hujan sebelum sampai di permukaan tanah, misalnya dengan menutup permukaan tanah (Agus dan Widianto 2004).

\subsection{Erodibilitas Tanah}

Erodibilitas tanah merupakan salah satu faktor yang menentukan besarnya erosi yang terjadi pada suatu lahan di samping faktor-faktor lainnya. Menurut
Arsyad (2006), erodibilitas atau kepekaan erosi tanah yaitu mudah atau tidaknya tanah tererosi merupakan fungsi berbagai interaksi sifat-sifat fisik dan kimia tanah. Sifat yang dimaksud adalah (1) sifat-sifat tanah yang mempengaruhi infiltrasi, permeabilitas dan kapasitas menahan air, (2) sifat-sifat tanah yang mempengaruhi ketahanan struktur tanah terhadap dispersi dan penghancuran agregat tanah oleh tumbukan butir-butir hujan dan aliran permukaan. Nilai erodibilitas tanah (K) dihitung berdasarkan hasil analisis masing-masing sampel tanah di laboratorium terhadap tekstur, struktur dan permeabilitas serta kandungan C-organik. Nilai erodibilitas tanah pada masing-masing sampel disajikan pada Tabel 4.

Tabel 4. Nilai erodibilitas tanah $(\mathrm{K})$

\begin{tabular}{|c|c|c|c|c|c|c|c|}
\hline \multirow{2}{*}{ Sampel } & \multicolumn{3}{|c|}{ Tekstur } & \multirow{2}{*}{ Struktur } & \multirow{2}{*}{$\begin{array}{c}\text { Permeabilitas } \\
\text { (cm/jam) }\end{array}$} & \multirow{2}{*}{$\begin{array}{c}\% \mathrm{C} \\
\text { organik }\end{array}$} & \multirow{2}{*}{$\begin{array}{c}\text { Erodibilitas } \\
\text { tanah }(\mathbf{K})\end{array}$} \\
\hline & $\%$ pasir & \%debu & $\%$ liat & & & & \\
\hline A1 & 85 & 6 & 9 & Granular & 7.05 & 0.63 & 0.35 \\
\hline $\mathrm{A} 2$ & 86 & 7 & 7 & Granular & 23.52 & 0.48 & 0.34 \\
\hline A3 & 86 & 4 & 10 & Granular & 19.80 & 0.57 & 0.30 \\
\hline B1 & 90 & 2 & 8 & Granular & 44.51 & 0.38 & 0.28 \\
\hline $\mathrm{B} 2$ & 86 & 1 & 13 & Granular & 26.45 & 0.19 & 0.23 \\
\hline B3 & 89 & 1 & 10 & Granular & 56.67 & 0.45 & 0.25 \\
\hline
\end{tabular}

Sumber: Analisis Laboratorium dan Data Primer (2014)

Menyajikan Selain nilai K, dari Tabel 4 dapat dilihat beberapa sifat tanah yang mempengaruhi erodibilitas seperti tekstur, struktur, permeabilitas dan C-organik. Berdasarkan tabel tersebut, sampel tanah pada semua lokasi bertekstur kasar dimana kandungan pasir lebih dominan dibandingkan kandungan debu dan liat. Kandungan pasir pada semua sampel diatas $80 \%$ yaitu antara $85-90 \%$. Kandungan pasir tertinggi terdapat pada sampel B1 $(90 \%)$ dan terendah terdapat pada sampel A1 (85\%). Tanah yang memiliki kandungan pasir tinggi lebih resisten terhadap erosi karena tanah tersebut memiliki kapasitas infiltrasi yang tinggi. Struktur tanah pada semua sampel termasuk granular butir sedang (2-5 mm). Tanah dengan struktur tersebut mengandung banyak pori-pori yang besar dan kapasitas infiltrasi yang tinggi dikarenakan antara partikel yang satu dengan lainnya tidak memiliki daya ikat yang besar. Nilai permeabilitas berkisar antara 7.05-56.67 $\mathrm{cm} / \mathrm{jam}$ termasuk kelas sedang sampai dengan cepat. Tingginya nilai permeabilitas ini dikarenakan tanah memiliki tekstur yang kasar dimana sebagian besar terdiri dari pasir. Kandungan C-organik dalam sampel berkisar antara 0.19-0.63\%. Kandungan C-organik tertinggi terdapat pada sampel A1 $(0.63 \%)$ dan terendah terdapat pada sampel B2 $(0.19 \%)$. Rendahnya kandungan C-organik ini dikarenakan tanah yang mengandung banyak pasir mempunyai oksidasi yang baik sehingga bahan organik cepat habis. Selain itu, pengupasan tanah pada saat penambangan pasir berlangsung menyebabkan hilangnya tanah lapisan atas (top soil) dan lapisan bawah (sub soil) yang banyak mengandung bahan organik. Semakin rendah kandungan bahan organik maka tanah semakin rentan terhadap erosi karena bahan organik berperan dalam membentuk agregat tanah.

Nilai K pada semua sampel tanah berkisar antara 0.23-0.35. Nilai K terbesar pada sampel A1 dan terkecil pada sampel B2. Besarnya nilai $\mathrm{K}$ ini dipengaruhi oleh beberapa sifat tanah tersebut. Semakin besar nilai K maka tanah semakin mudah tererosi, sebaliknya semakin kecil nilai K maka tanah semakin tahan terhadap erosi. Menurut Agus dan Widianto (2004), erodibilitas tanah dapat diperbaiki dengan meningkatkan kandungan bahan organik dan memperbaiki struktur tanah.

\subsection{Kemiringan Lereng}

Lokasi penelitian berada pada kemiringan 0-8\% dan $8-15 \%$. Nilai faktor lereng (LS) pada kemiringan 0-8\% adalah 0.25 dan pada kemiringan $8-15 \%$ adalah 1.20 . Peluang terjadinya erosi makin besar dengan makin curamnya lereng. Hal ini dikarenakan semakin curamnya lereng akan memperbesar energi angkut air sehingga jumlah butir-butir tanah yang terpercik ke bawah oleh tumbukan air semakin banyak (Nursa'ban 2006). 


\subsection{Vegetasi Penutup dan Pengelolaan Tanah}

Lokasi penambangan merupakan tanah terbuka tanpa tanaman, semuanya sudah menjadi lahan pasir sehingga tidak ada vegetasi penutup tanah yang melindungi permukaan tanah dari tumbukan air hujan. Pada kondisi ini butir-butir hujan yang jatuh langsung mengenai tanah, sehingga tumbukan air hujan ke tanah sangat besar.

\subsection{Laju Erosi dan Tingkat Bahaya Erosi (TBE)}

Besarnya laju erosi diperoleh dengan mengalikan faktor-faktor yang mempengaruhi erosi pada masingmasing lokasi. Hasil perhitungan menunjukan bahwa besarnya laju erosi pada masing-masing lokasi berbeda. Lokasi A1, A2 dan A3 yang berada pada kemiringan 8$15 \%$ memiliki laju erosi lebih besar dengan kisaran 1,023.57-1,194.16 ton/ha/tahun. Lokasi B1, B2 dan B3 yang berada pada kemiringan 0-8\% memiliki laju erosi lebih kecil berkisar antara 163.49-199.03 ton/ha/tahun. Laju erosi terbesar terjadi pada lokasi A1 dan terkecil terjadi pada lokasi B1. Perbedaan nilai erosi tersebut cenderung dipengaruhi oleh perbedaan tingkat kemiringan lereng sehingga nilai LSnya pun berbeda. Semakin besar tingkat kemiringan lereng maka semakin besar pula nilai LSnya yang menyebabkan semakin besarnya laju erosi. Nilai laju erosi yang tinggi ini sejalan dengan hasil penelitian pada lokasi penambangan pasir lainnya oleh Dyahwanti (2007) di Gunung Sumbing, Kabupaten Temanggung yang menunjukan bahwa besarnya laju erosi sekitar 87.553-202.828 ton/ha/tahun dan hasil penelitian Yudhistira (2008) di Gunung Merapi, Kabupaten Magelang yang menunjukkan bahwa besarnya laju erosi sekitar 259,909.47$1,118,628.8$ ton/ha/tahun.

TBE ditentukan berdasarkan pendekatan tebal solum tanah sesuai dengan kriteria Departemen Kehutanan (1986). TBE untuk semua lokasi tergolong sangat berat. Berdasarkan hasil tersebut, maka diperlukan upaya konservasi lahan untuk mengurangi laju erosi sampai pada tingkat yang aman. Upaya konservasi lahan yang dapat dilakukan adalah dengan segera melakukan penanaman tanaman penutup tanah pada lahan yang telah selesai diekploitasi dengan teknik konservasi yang disesuaikan dengan jenis tanaman yang ditanam. Laju erosi dan Tingkat Bahaya Erosi (TBE) pada setiap lokasi disajikan pada Tabel 5.

Tabel 5. Laju erosi dan Tingkat Bahaya Erosi (TBE)

\begin{tabular}{|c|c|c|c|c|c|c|c|c|}
\hline Lokasi & $\begin{array}{c}\text { R } \\
\text { (MJ mm/ha/jam/tahun) }\end{array}$ & $\begin{array}{c}\mathrm{K} \\
\text { (ton ha jam/MJ/mm/ha) }\end{array}$ & $\mathbf{L S}$ & $\mathbf{C}$ & $\mathbf{P}$ & $\begin{array}{c}\text { A } \\
\text { (ton/ha/tahun) }\end{array}$ & $\begin{array}{c}\text { Tebal solum } \\
(\mathrm{cm})\end{array}$ & TBE \\
\hline A1 & $2,843.24$ & 0.35 & 1.20 & 1.00 & 1.00 & $1,194.16$ & 70 & $\begin{array}{c}\text { Sangat } \\
\text { Berat }\end{array}$ \\
\hline $\mathrm{A} 2$ & $2,843.24$ & 0.34 & 1.20 & 1.00 & 1.00 & $1,160.04$ & 73 & $\begin{array}{c}\text { Sangat } \\
\text { Berat }\end{array}$ \\
\hline A3 & $2,843.24$ & 0.30 & 1.20 & 1.00 & 1.00 & $1,023.57$ & 43 & $\begin{array}{c}\text { Sangat } \\
\text { Berat }\end{array}$ \\
\hline B1 & $2,843.24$ & 0.28 & 0.25 & 1.00 & 1.00 & 199.03 & 67 & $\begin{array}{c}\text { Sangat } \\
\text { Berat }\end{array}$ \\
\hline B2 & $2,843.24$ & 0.23 & 0.25 & 1.00 & 1.00 & 163.49 & 30 & $\begin{array}{c}\text { Sangat } \\
\text { Berat }\end{array}$ \\
\hline B3 & $2,843.24$ & 0.25 & 0.25 & 1.00 & 1.00 & 177.70 & 32 & $\begin{array}{c}\text { Sangat } \\
\text { Berat }\end{array}$ \\
\hline
\end{tabular}

Sumber: Analisis Data Primer (2014)

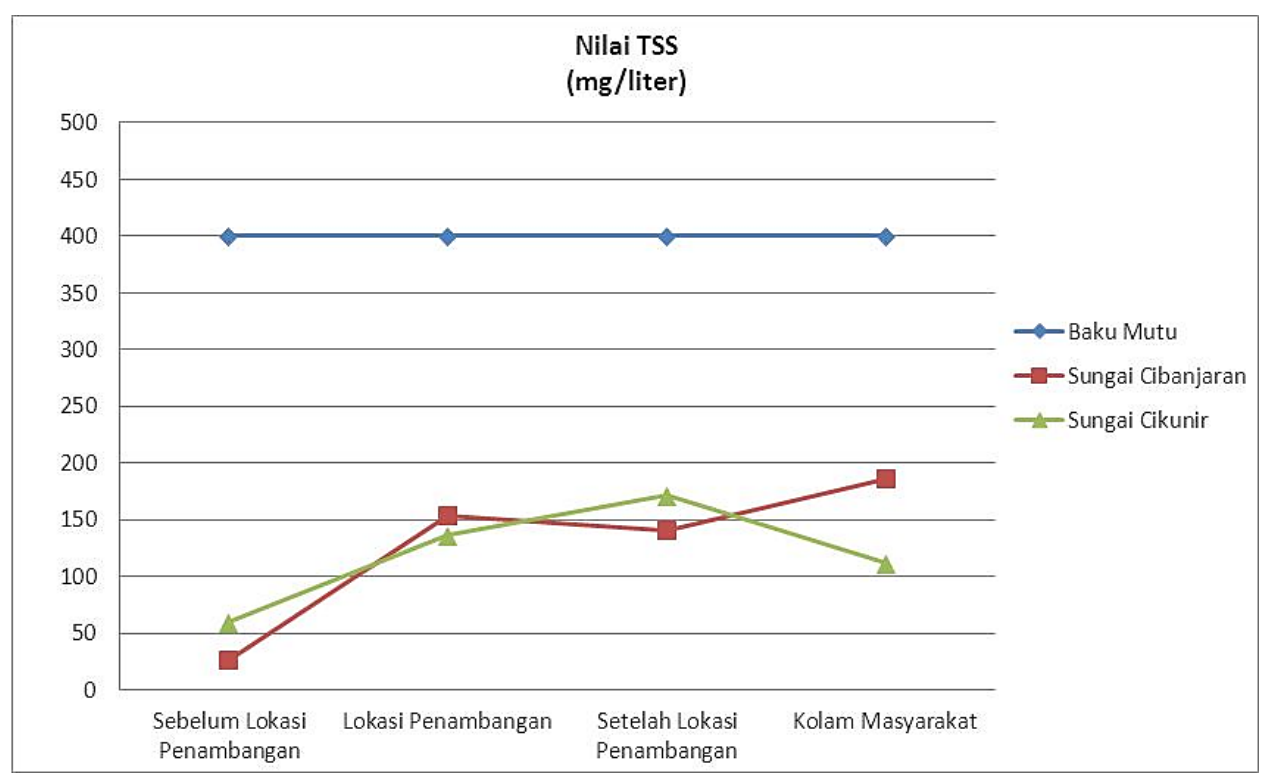

Gambar 2. Hasil pengujian Total Suspended Solid (TSS) 


\subsection{Total Suspended Solid (TSS)}

Pertambangan terbuka merupakan sumber pencemar yang menimbulkan kerusakan paling tinggi berupa pelumpuran dan kekeruhan (Yunus 2005; Saviour 2012). Padatan tersuspensi total atau Total Suspended Solid (TSS) adalah bahan-bahan tersuspensi (diameter $>1 \mu \mathrm{m}$ ) dalam air yang terdiri dari lumpur dan pasir halus serta jasad-jasad renik yang terbawa ke badan air (Effendi 2003).

Pencucian merupakan salah satu proses dalam penambangan pasir Galunggung. Proses ini dilakukan dengan tujuan untuk memisahkan pasir dari unsur-unsur lainnya sehingga menghasilkan pasir yang lebih berkualitas dan sisa pencucian berupa lumpur dan pasir halus. Penurunan kualitas air sungai dikarenakan adanya sisa pencucian pasir yang terbuang ke sungai. Sungai yang berada di sekitar lokasi penambangan adalah Sungai Cibanjaran dan Cikunir. Hasil pengujian TSS pada Sungai Cibanjaran dan Cikunir yang dibandingkan dengan baku mutu disajikan pada Gambar 2 .

Pada Gambar 2, nilai TSS berkisar antara 26-186 mg/liter. Nilai TSS sebelum lokasi penambangan lebih kecil dibandingkan nilai TSS di lokasi penambangan dan setelah lokasi penambangan. Nilai TSS sebelum lokasi penambangan untuk Sungai Cibanjaran sebesar 26 $\mathrm{mg} / \mathrm{liter}$ dan meningkat hampir 6 kali lipatnya menjadi $154 \mathrm{mg} /$ liter di lokasi penambangan. Nilai TSS sebelum lokasi penambangan untuk Sungai Cikunir sebesar $60 \mathrm{mg} / \mathrm{liter}$ dan meningkat menjadi $136 \mathrm{mg} / \mathrm{liter}$ di lokasi penambangan.

Tingginya nilai TSS di lokasi penambangan dan setelah lokasi penambangan dikarenakan adanya penambahan partikulat yaitu lumpur dan pasir halus sisa pencucian pasir yang terbuang ke sungai. Semakin banyaknya volume pasir yang diambil maka semakin tinggi nilai TSS di kedua sungai. Begitu pula pada kolam masyarakat yang sumber airnya berasal dari Sungai Cibanjaran dan Cikunir mempunyai nilai TSS yang tinggi. Selain faktor yang telah disebutkan di atas, hal ini dikarenakan adanya faktor lain yang turut memperbesar nilai TSS yaitu pakan ikan dan limbah domestik (rumah tangga) yang dibuang ke kolam tersebut.

Baku mutu yang digunakan mengacu pada Peraturan Pemerintah Nomor 82 Tahun 2001 tentang Pengelolaan Kualitas Air dan Pengendalian Pencemaran Air untuk kategori mutu air kelas III. Pemilihan kategori kelas mutu air dilihat dari penggunaannya yaitu untuk pertanian dan perikanan air tawar. Nilai TSS pada Sungai Cibanjaran dan Cikunir masih dibawah baku mutu (nilai TSS minimal $400 \mathrm{mg} /$ liter) sebagaimana yang tercantum pada peraturan tersebut.

Alabaster dan Lloyd (1982) dalam Effendi (2003) mengemukakan tentang kriteria kesesuaian perairan untuk kepentingan perikanan berdasarkan nilai TSS. Nilai TSS $<25 \mathrm{mg} /$ liter tidak berpengaruh terhadap kepentingan perikanan, antara 25-80 mg/liter memberikan sedikit pengaruh terhadap kepentingan perikanan, antara 81-400 mg/liter kurang baik bagi kepentingan perikanan dan $>400 \mathrm{mg} / \mathrm{liter}$ tidak baik 104 bagi kepentingan perikanan. Berdasarkan kriteria tersebut, walaupun nilai TSS pada hasil pengujian masih dibawah baku mutu yang dipersyaratkan dalam Peraturan Pemerintah Nomor 82 Tahun 2001 akan tetapi air dengan nilai TSS tersebut kurang baik bagi kepentingan perikanan.

Apabila nilai TSS tinggi maka akan meningkatkan kekeruhan sehingga menghambat penetrasi cahaya matahari dan mengganggu sistem osmoregulasi hewan air. Menurut Fardiaz (2003) dan Saviour (2012), sedimen yang masuk ke badan perairan meliputi tanah dan pasir bersifat tersuspensi. Sedimen menyebabkan hilangnya tempat memijah yang sesuai bagi ikan karena sedimen dapat menutupi substrat sehingga organisme yang membutuhkan substrat sebagai tempat hidupnya dan tempat berlindung menjadi terganggu.

\section{Kesimpulan}

Berdasarkan penelitian yang telah dilakukan maka dapat disimpulkan bahwa penambangan pasir di Kecamatan Sukaratu berdampak negatif pada kondisi lahan dan air. Laju erosi pada lokasi penambangan pasir berkisar antara 163.49-1,194.16 ton/ha/tahun dengan Tingkat Bahaya Erosi (TBE) tergolong sangat berat. Nilai Total Suspended Solid (TSS) Sungai Cibanjaran dan Cikunir berkisar antara 26-186 mg/liter, nilai ini masih dibawah baku mutu, akan tetapi berpengaruh kurang baik untuk perikanan.

\section{Daftar Pustaka}

[1] Agus, F., Widianto, 2004. Petunjuk Praktis: Konservasi Tanah Pertanian Lahan Kering. World Agroforestry Centre (ICRAF), South East Regional Office, Bogor.

[2] Arsyad, S., 2006. Konservasi Tanah dan Air. Edisi ke-2. IPB Press, Bogor.

[3] [BPS Kab. Tasikmalaya] Badan Pusat Statistika Kabupaten Tasikmalaya, 2012. Kabupaten Tasikmalaya dalam Angka (Tasikmalaya in Figure) 2012. BPS Kab. Tasikmalaya, Tasikmalaya.

[4] Dariah, A., A. Rachman, U. Kurnia, 2004. Erosi dan Degradasi Lahan Kering di Indonesia. Balai Penelitian Tanah, Bogor.

[5] Dyahwanti, I. N., 2007. Kajian dampak lingkungan kegiatan penambangan pasir pada daerah sabuk hijau Gunung Sumbing di Kabupaten Temanggung. Tesis. Sekolah Pascasarjana, Universitas Dipenogoro, Semarang.

[6] Effendi, H., 2003. Telaah Kualitas Air: Bagi Pengelolaan Sumber Daya dan Lingkungan Perairan. Kanisius, Yogyakarta.

[7] Fardiaz, S., 2003. Polusi Air dan Udara. Kanisius, Yogyakarta.

[8] Hardjowigeno, S., Widiatmaka, 2007. Evaluasi Kesesuaian Lahan dan Perencanaan Tataguna Lahan. Gadjah Mada University Press, Yogyakarta.

[9] Hasibuan, P. M., 2006. Dampak penambangan bahan galian golongan $\mathrm{C}$ terhadap lingkungan sekitarnya di Kabupaten Deli Serdang. Jurnal Equality 11 (1), pp. 26-32.

[10]Nursa'ban, M., 2006. Pengendalian erosi tanah sebagai upaya melestarikan kemampuan fungsi lingkungan. Jurnal Geomedia 4 (3), pp. 93-116.

[11]Peraturan Pemerintah, 2001. Lampiran Peraturan Pemerintah Nomor 82 Tahun 2001. Tanggal 14 Desember 2001. 
[12] Saviour, M. N., 2012. Environmental impact of soil and sand mining: a review. International Journal of Science, Environment and Technology 1 (3), pp. 125-136.

[13] Sonak, S., P. Pangam, M. Sonak, D. Mayekar, 2006. Impact of Sand Mining on Local Ecology in "Multiple Dimensions of Global Environmental Change". The Energy and Resources Institute, New Delhi.

[14] Widyati, E., T. Rostiwati, 2010. Menelaah kerusakan lingkungan akibat pertambangan mineral. Mitra Hutan Tanaman 5(2), pp. 121-128.

[15] Yudhistira, 2008. Kajian dampak kerusakan lingkungan akibat kegiatan penambangan pasir di daerah Kawasan Gunung Merapi (Studi kasus di Desa Keningar Kecamatan Dukun Kabupaten Magelang, Propinsi Jawa Tengah). Tesis. Sekolah Pascasarjana, Universitas Dipenogoro, Semarang.

[16] Yunus, L., 2005. Evaluasi kerusakan Daerah Aliran Sungai (DAS) Citanduy Hulu dan akibatnya di hilir. Tesis. Sekolah Pascasarjana, Institut Pertanian Bogor, Bogor 